\title{
The Influence of Titania Electrode Modification with Lanthanide Ions Containing Thin Layer on the Performance of Dye-Sensitized Solar Cells
}

\author{
Maciej Zalas ${ }^{1}$ and Maciej Klein ${ }^{2}$ \\ ${ }^{1}$ Faculty of Chemistry, Adam Mickiewicz University, Umultowska 89b, 61-614 Poznań, Poland \\ ${ }^{2}$ Faculty of Applied Physics and Mathematics, Gdansk University of Technology, G. Narutowicza 11/12, 80-233 Gdańsk, Poland \\ Correspondence should be addressed to Maciej Zalas, maciej.zalas@amu.edu.pl
}

Received 27 August 2012; Revised 5 October 2012; Accepted 12 October 2012

Academic Editor: Lukas Schmidt-Mende

Copyright $\odot 2012$ M. Zalas and M. Klein. This is an open access article distributed under the Creative Commons Attribution License, which permits unrestricted use, distribution, and reproduction in any medium, provided the original work is properly cited.

\begin{abstract}
The lanthanide and scandium groups ions (except Pm and Ac) have been used as dopants of $\mathrm{TiO}_{2}$ film in dye-sensitized solar cells. The X-ray diffraction spectra show that the modification has no influence on the structure of the electrode; however, the diffuse reflectance UV-Vis measurements exhibit significant changes in the electronic properties of modified electrodes. The appearance of energy barrier preventing photoexcited electron back-transfer was confirmed for Sc, Ce, Sm, Tb, Ho, Tm, and Lu modified cells. The best photoconversion performance of 8.88 and $8.80 \%$ was found for samples modified with Ce and $\mathrm{Yb}$, respectively, and it was greater by 31.4 and $30.2 \%$ than that of a unmodified cell.
\end{abstract}

\section{Introduction}

Since 1991, when the pioneering work was reported by O'Regan and Grätzel [1], dye-sensitized solar cells (DSSCs) have been intensively studied as a low-cost alternative to conventional silicon solar cells. The main advantage of DSSCs is the possibility of using for their synthesis the materials of low or medium purity prepared in a standard laboratory conditions with no need for any hi-clean technologies, which are necessary for silicon solar cells production [2]. The photoconversion efficiencies reaching over $12 \%$ for small cells and about $9 \%$ for modules, connected with high stability upon sunlight exposure, make DSSC technology most promising for generation of energy from renewable sources on a large scale [3].

The typical DSSC is composed of four main parts:

(i) a sheet of conducting glass (TCO) covered with porous semiconducting anode (mostly $\mathrm{TiO}_{2}$, rarely $\mathrm{ZnO}[3]$ ),

(ii) a monolayer of photosensitive dye adsorbed on the anode surface (mostly polypyridine $\mathrm{Ru}$ complexes $[4])$, (iii) a liquid electrolyte containing redox medium (usually $\left.\mathrm{I}^{-} / \mathrm{I}^{3-}[5]\right)$,

(iv) a sheet of TCO covered with a thin layer of platinum or graphite [3] (a counter electrode).

In the beginning of the photoelectric process occurring in DSSC, a photon of the incident light is absorbed by the dye molecule, which is excited from its ground to excited state. The excited electron is injected from the dye molecule into the conducting band of the porous semiconducting electrode, and in consequence, the dye gets oxidized. Electron from the porous layer migrates to the TCO substrate and is transferred to the counter electrode through the external circuit, where it is used to reduce the oxidized form of the redox couple present in the electrolyte. Simultaneously the ground state of the dye molecule is restored by electron transferred from the reduced form of the redox couple and the DSSC working cycle is closed. In the ideal system the whole operation process takes place without consumption nor permanent transformation of any chemical species, and theoretically, it can occur until illumination is present. Unfortunately, in real systems there are some undesirable electron transfer pathways, which cause some losses. 
The excited dye molecules can directly recombine to reproduce the dye molecule ground state, and the absorbed energy is usually emitted as heat. Another unwanted process in DSSC is the recombination of the electron injected into the semiconductor conduction band with the oxidized form of the dye. The main cause of loses is the interactions between the semiconductor nanoparticles and the redox mediator in the electrolyte. The processes described above cause a considerable decrease in the cell performance, and much attention is paid to ways of prevention of these phenomena $[2,3,5-9]$.

For improvement of electron, injection efficiency or electron lifetime in the electrode, some postsynthesis-treatment methods have been applied. The most common methods were deposition of a thin layer $\mathrm{TiO}_{2}$ on the electrode external surface using $\mathrm{TiCl}_{4}$ aqueous solution treatment or $\mathrm{TiCl}_{3}$ electrodeposition. The modification resulted also in an increased amount of the dye adsorbed [3]. Modification of $\mathrm{TiO}_{2}$ electrodes by covering them with a thin layer of an insulator or other semiconductor can create an energetic barrier for the electron back-transfer and improves the photoelectrical properties of DSSC. When the modifying semiconductor has a slightly more negative potential of the conduction band level than $\mathrm{TiO}_{2}$, but less negative than the excited state of the sensitizing dye, the photoexcited electrons can still be easily injected into the $\mathrm{TiO}_{2}$ conduction band through the external modification of the semiconductor layer. After the injection process, the energy of the electrons present in $\mathrm{TiO}_{2}$ conduction band corresponds to that of the bandgap of the external semiconductor and this is an inherent barrier for the electrode-electrolyte recombination process. The electrons trapped in the conduction band of $\mathrm{TiO}_{2}$ can be easily transferred to TCO and used for the next steps of the photoelectric process, taking place in DSSC [1013].

To date, lanthanide elements (the so-called rare-earths elements (REs)), which have been widely used as a dopants in $\mathrm{TiO}_{2}$ in highly efficient light conversion devices $[14,15]$, have been rather rarely applied in DSSCs. The survey of the literature on RE applications in DSSCs shows that introduction of RE into the photoanode of DSSCs endows it with novel properties and may translate to better performance of the cells. Yao et al. have reported on monodispersed Nddoped $\mathrm{TiO}_{2}$ nanorods synthesized by solvothermal method [16]. The devices consisting of modified nanorods exhibited a $33 \%$ increase in overall photoconversion efficiency under illumination with monochromatic light in the range 400$800 \mathrm{~nm}$, when compared with those devices, in which unmodified $\mathrm{TiO}_{2}$ nanorods were applied. Doping of the $\mathrm{TiO}_{2}$ photoelectrodes with $\mathrm{Eu}^{3+}$ and $\mathrm{Sm}^{3+}$ ions, during their synthesis, also brings a considerable increase in the cell parameters [17]. These devices show efficiencies of 5.81\% and $5.16 \%$ when doped with $\mathrm{Eu}^{3+}$ and $\mathrm{Sm}^{3+}$ ions respectively, while the undoped DSSC shows an efficiency of $4.23 \%$ under illumination in AM 1.5 conditions. Incorporation of $\mathrm{Eu}^{3+}$ ions into $\mathrm{TiO}_{2}$ electrode has been studied by a few authors and has always led to enhanced photoelectrical performance of DSSCs [18-20]. On the other hand, the doping of $\mathrm{TiO}_{2}$ nanoporous films with $\mathrm{Yb}^{3+}$ ions, reported by Xu et al. [21], leads to a decrease in the overall efficiency with a simultaneous increase in the open circuit photovoltage $\left(V_{\mathrm{oc}}\right)$ and fill factor $(\mathrm{FF})$ of the obtained devices under simulated AM 1.5 irradiation conditions. However, the use of $\mathrm{Yb}^{3+}$ ions as $\mathrm{TiO}_{2}$ codopants with $\mathrm{Tm}^{3+}[22,23]$ or $\mathrm{Er}^{3+}$ [24-26] ions, to form the scattering layer in DSSC electrodes causes an increase in the cells performance.

Another type of incorporation of RE into DSSC devices is in an external layer containing compounds of pure RE or $\mathrm{RE}$ ions as a dopants. Photoanodes of hybrid $\mathrm{TiO}_{2} / \mathrm{La}_{3} \mathrm{O}_{3}$ prepared by modification of $\mathrm{TiO}_{2}$ films via dip coating in the isopropanolic $\mathrm{La}^{3+}$ solution have been studied by $\mathrm{Yu}$ et. al. [27]. The modifying $\mathrm{La}_{2} \mathrm{O}_{3}$ layer plays a role of the electrode-electrolyte recombination barrier and its presence improved the DSSC efficiencies from $6.84 \%$ to $9.67 \%$ for the control $\mathrm{TiO}_{2}$ film and the $\mathrm{La}^{3+}$-modified film, respectively. A similar approach has been applied to modify $\mathrm{ZnO}$ electrodes by dipping in aqueous solutions of $\mathrm{La}, \mathrm{Ce}, \mathrm{Nd}, \mathrm{Sm}$ and Gd-nitrates, in the work reported by $\mathrm{Lu}$ and co-workers [28]. Only Sm and Gd modified electrodes showed better performance, 1.52 and $1.98 \%$, respectively, than that of unmodified $\mathrm{ZnO}$ electrode (1.37\%). Modification with $\mathrm{La}$, $\mathrm{Ce}$, and $\mathrm{Nd}$ compounds leads to deterioration of the cell parameters. Photochemical measurements were made using a class A solar simulator.

In our previous study [29] we have reported the increase in the efficiency of DSSC obtained by modification of the porous $\mathrm{TiO}_{2}$ layer with $\mathrm{Gd}$-containing thin $\mathrm{TiO}_{2}$ layer. The modification resulted in a $35 \%$ improvement in photoconversion efficiency, under illumination with tungsten halogen lamp with light intensity $400 \mathrm{~W} / \mathrm{m}^{2}$, when compared with unmodified device. Taking in the regard the results of our earlier study, in this paper, we propose the use of porous $\mathrm{TiO}_{2}$ electrodes modified with all RE elements (except Pm because of its natural radioactivity) and additionally with Sc, Y, and La elements, and the influence of these modifications on the DSSC performances, characterized under simulated AM $1.5 \mathrm{G}$ conditions using a class A solar simulator, is checked.

\section{Experimental Details}

All chemicals used were in analytical grade and were used as received without any additional purification. The procedure used for preparation of the lanthanide-modified titania electrodes was similar to those described elsewhere $[29,30]$ and was as follows $3 \mathrm{~mL}$ titanium tetraisopropoxide (Aldrich) were added to $13.5 \mathrm{~mL}$ of ethylene glycol (Chempur) magnetically stirred at $333 \mathrm{~K}$. The mixture, after addition of $12.6 \mathrm{~g}$ of citric acid monohydrate $(\mathrm{POCh})$, was heated under stirring at $363 \mathrm{~K}$, until clear. The transparent sol obtained was mixed with $5.6 \mathrm{~g} \mathrm{P} 25 \mathrm{TiO}_{2}$ (Degussa) by grinding in agate mortar for 1 hour. The viscous titania paste obtained was spread on fluorine doped tin oxide (FTO) conductive glass substrate (Solaronix) using "doctor blading" technique and sintered in air at $723 \mathrm{~K}$ for 1 hour. The electrodes obtained were labeled as "Ti" and were used as a reference and base for further modifications with lanthanide-containing thin layer according to the following procedure: a sample weight of lanthanide oxide (Stanford Materials Corp.) was 
added to $20 \mathrm{~mL}$ of $65 \%$ nitric acid (Chempur) and boiled to complete dissolution. The $\mathrm{Ln}^{3+}$ solution was concentrated to about 2-3 $\mathrm{mL}$ and diluted with distilled water; this procedure was repeated three times to ensure complete evaporation of nitric acid; the final solution was diluted with distilled water to $50 \mathrm{~mL}$ and the final concentration of $\mathrm{Ln}^{3+}$ was $0.2 \mathrm{M}$. To this solution, $1.1 \mathrm{~mL}$ of titanium tetrachloride (Fluka) was added under vigorous stirring. Ti electrodes were dipped in the obtained $\mathrm{TiCl}_{4} / \mathrm{Ln}^{3+}$ solution for 1 hour, washed with distilled water, and sintered in air at $723 \mathrm{~K}$ for $30 \mathrm{~min}$. The dipping procedure was repeated twice for each type of modification. The modified electrodes obtained were labeled using a chemical symbol of the element used to prepare a modifying mixture (e.g., Sc for scandium modified electrode, Ce for cerium modified electrode, $\mathrm{Sm}$ for samarium modified electrode, etc.).

The amount of a lanthanide element on the particular modified electrode was determined by ICP-OES technique. The samples were prepared by scratching electrode materials from the FTO substrates and the powders obtained were extracted by boiling for 2 hours under reflux with $1 \mathrm{~mL}$ of $65 \%$ nitric acid. The suspension were filtered on the Whatman GF/A glass microfibre filters (Whatman) and the filters were washed with a small amount of distilled water. The solutions after filtration were dissolved with distilled water to $10 \mathrm{~mL}$ and used in ICP-OES measurements.

To prepare working electrodes for DSSCs, modified and unmodified titania electrodes were immersed in $1 \cdot 10^{-4} \mathrm{M}$ ethanol solution of $\mathrm{N} 3$ dye (Solaronix) at $5^{\circ} \mathrm{C}$ for 24 hours. After dye adsorption, the electrodes were washed with absolute ethanol and dried in hot air stream. To determine the amount of dye absorbed, the sensitized electrodes were immersed in $5 \mathrm{~mL}$ of $0.1 \mathrm{M} \mathrm{NH}_{4} \mathrm{OH}$ in water:ethanol 1:1 solution for $10 \mathrm{~min}$. Concentration of the desorbed dye in the solution left was determined by UV-Vis technique. Platinum film coated FTO was used as a counter electrode. The typical cell was assembled using a $25 \mu \mathrm{m}$ thick, hotmelted, ionomeric foil (Solaronix) as a sealant, and a spacer between the electrodes and an electrolyte (a mixture of 0.6 M 1-propyl-3-methyl-imidazolium iodide (Aldrich), $0.03 \mathrm{M}$ iodine (POCh), $0.1 \mathrm{M}$ guanidine thiocyanate (Fluka), and $0.5 \mathrm{M}$ 4-tert-butylpiridine (Aldrich) in acetonitrile (Merck)) was injected within two holes predrilled in the counter electrode. The final sealing was realized with the use of hot-melted sealant and a microscope cover slide. The typical active area of the obtained DSSC was approximately $0.125 \mathrm{~cm}^{2}$. Each type of DSSC prepared was reproduced 5 times and photoelectric measurements were repeated 5 times, for every cell prepared, so that each final result of photovoltaic performance presented is an average of 25 photoelectric experiments.

XRD measurements were performed on a D8 Advance diffractometer (Bruker) with $\mathrm{Cu} \mathrm{K} \alpha(\lambda=0.15406 \mathrm{~nm})$ radiation, transmittance UV-Vis experiments were carried out on a Cary 50 Probe spectrometer (Varian), diffuse reflectance UV-Vis experiments were carried out on a Cary 5000 spectrometer equipped with integrating sphere (Varian), and the inductively coupled plasma-optical emission spectroscopy (ICP-OES) analyses were made on
Vista-MPX spectrometer (Varian). The electrochemical impedance spectra were measured using an impedance analyzer SI 1260 (Solatron) with electrochemical interface SO 1255 . The frequency range was $0.1 \mathrm{~Hz}-1 \mathrm{MHz}$, and ac amplitude $V_{\mathrm{ac}}=5 \mathrm{mV}$. During measurements the cell was irradiated using a $50 \mathrm{~W}$ halogen lamp (tungsten filament) with reflector and parabolic mirror. Between the light source and cell there was placed a water filter. Light intensity was calibrated to $70 \mathrm{~mW} / \mathrm{cm}^{2}$ using a FieldMate power meter (Coherent).

The photovoltaic performance of the cells obtained was measured using a Sun 2000 class A Solar Simulator (Abet Technologies) equipped with an AM $1.5 \mathrm{G}$ filter, with the light intensity adjusted at $100 \mathrm{mWcm}^{-2}$ using a silicon reference cell (ReRa Systems). $J$ - $V$ curves were recorded on a Keithley 2400 SourceMeter (Keithley).

\section{Results and Discussion}

The presence and amount of lanthanide elements on the modified electrodes were determined via ICP-OES experiments, which gave the concentration of RE of about 0.05 (0.002) wt. \%, with reference to the total mass of the material scratched from a particular electrode.

The XRD patterns selected, are presented in Figure 1, shows that the electrodes have a typical crystalline structure characteristic of the $\mathrm{P} 25 \mathrm{TiO}_{2}$, which is a mixture of the anatase and rutile phases at a rate around 3:1 [31]. Additional reflexes, which can be seen in the XRD patterns are characteristic of FTO substrate. The XRD patterns of none of the modified electrodes show reflexes corresponding to the crystallographic structures of the modified elements (RE), their oxides, or other their compounds, which can be explained by uniform dispersion of $\operatorname{RE}[16,28]$ and/or by formation of amorphous phase of $\operatorname{RE}[16,21]$ or more probably by a low concentration of the RE doping in the electrodes studied $[21,28]$.

The semiconductor bandgap $\left(E_{g}\right)$ is an important parameter, which affects the rate of the electron-hole recombination process and light absorption properties of the photoactive materials [32]. The most widely used method of the semiconductors bandgap determination is a deduction of the bandgap value from the diffuse reflectance UV-Vis spectra of the semiconductor [32]. The widening and narrowing of the semiconductor bandgap has a strong influence on its electronic spectra observed as the blue shift and red shift, respectively, of the absorption edge in the UV-Vis spectra of the material. The exemplary UV-Vis spectra of selected electrodes are shown in Figure 2. When compared with Ti electrode, the Eu electrode shows a strong hypsochromic shift (blue shift), on other hand, Ce electrode shows the opposite effect, which is called a bathochromic shift (red shift). The effects mentioned above are strongly connected with the bandgap values of the RE electrodes investigated.

Figure 3 shows the diagram of bandgap values of the presented RE-modified electrodes determined via calculation from their UV-Vis spectra using the Kubelka-Munk function [33]. Graphical presentation of the $E_{g}$ values determination 


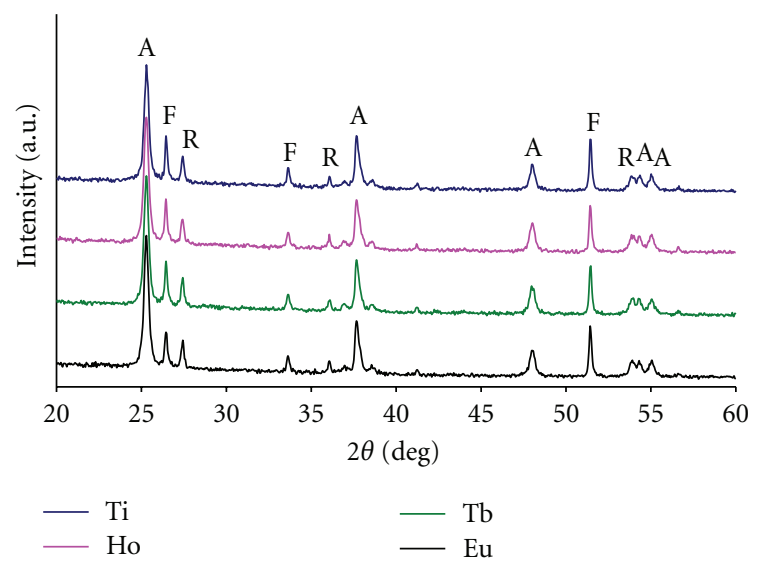

FIGURE 1: XRD patterns of selected electrodes. Reflexes are indicated as follows: A-anatase, R-rutile and F-FTO substrate.

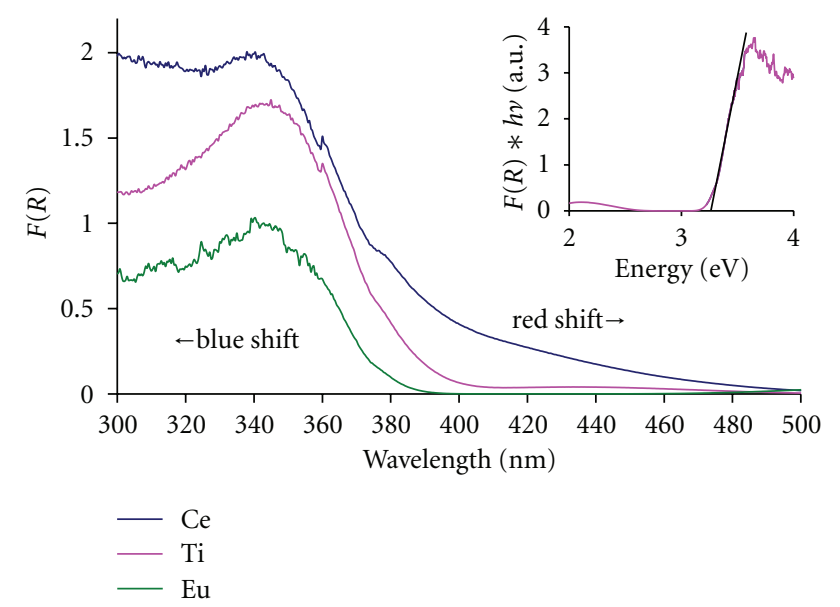

Figure 2: The UV-Vis spectra of selected RE electrodes (main plot) and graphical presentation of the bandgap determination for $\mathrm{Ti}$ electrode (insert).

is shown in the insert of Figure 2. The $E_{g}$ values are also collected in Table 1 . The $E_{g}$ value calculated for Ti electrode is $3.26 \mathrm{eV}$, which is a little bit higher than expected. As mentioned above, Ti electrode was prepared using $\mathrm{P} 25 \mathrm{TiO}_{2}$, which consist of anatase and rutile at a rate close to 3:1. The typical $E_{g}$ values of anatase and rutile are 3.2 and $3.0 \mathrm{eV}$, respectively $[32,34]$, so the expected $E_{g}$ value of $\mathrm{Ti}$ electrode should be between these two values. The most probable reason for a higher $E_{g}$ value in the material studied is a diffusion of $\mathrm{Sn}$ from the FTO substrate to the porous $\mathrm{TiO}_{2}$ layer during the sintering process [35]. The typical $E_{g}$ value of tin conductive oxide (TCO) is close to $4.18 \mathrm{eV}$ [36], so the migration of $\mathrm{Sn}$ species into the porous structure of the $\mathrm{TiO}_{2}$ electrode leads to a slight increase in its $E_{g}$ value. The bandgap values of the RE-modified electrodes are between 3.08, for Ce electrode and $3.33 \mathrm{eV}$ for $\mathrm{Eu}$ and Ho electrodes (see Table 1). The direction of changes in the bandgap values of the presented RE-doped $\mathrm{TiO}_{2}$, is in good agreement with literature data $[37,38]$. A considerable effect of the bandgap narrowing is observed for the Ce electrode.

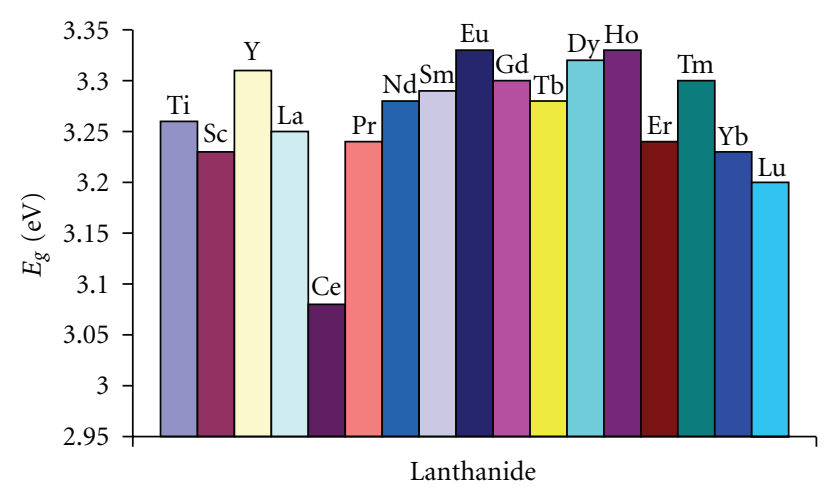

Figure 3: The comparison of the bandgap values of the investigated electrodes.

Chen et al. explain that a decrease in the bandgap width in the Ce-doped $\mathrm{TiO}_{2}$ is caused by the formation of an impurity band, composed of Ce $4 f$ and oxygen defect states [39]. The participation of Ce $4 f$ orbitals in the electron photoexcitation process also contributes to the electron-hole recombination decrease [40].

Electrochemical impedance spectroscopy has been widely used to characterize electron transport process occurring in DSSC [41]. Figure 4 shows the Nyquist Plots obtained for two selected RE-modified cells (Ce and $\mathrm{Yb}$ ) compared with the plot obtained for Ti cell, additionally the total resistance values $\left(R_{t}\right)$ measured for all cells investigated are collected in Table 1. The typical semicircles are clearly seen on the plots. The arcs in high frequency range represent the charge transfer process at the counter electrode and those in low frequencies are related to the charge transport process at the $\mathrm{FTO} /$ mesoporous electrode material/adsorbed dye/electrolyte interfaces and the ion diffusion process within the electrolyte. All RE cells studied exhibit changes in the $R_{t}$ values in comparison with Ti cell, but only 7 of them ( $\mathrm{Sc}, \mathrm{Ce}, \mathrm{Sm}, \mathrm{Tb}, \mathrm{Ho}, \mathrm{Tm}$, and $\mathrm{Lu}$ ) show an increase in $R_{t}$ value, which is expected as a result of formation of an external layer, which would be an energy barrier for the electron back-transfer process [42, 43]. As follows from the results obtained, the other RE modifications, excluding those mentioned above, do not lead to creation of an energy barrier at the $\mathrm{TiO}_{2}$ surface but to quite the opposite effects.

A comparison of the impedance spectroscopy results with the above $E_{g}$ values (see Table 1) shows that the electrode bandgap narrowing is not always connected with the formation of the electron-transfer blocking barrier. Ce modification, which leads to a considerable decrease in $E_{g}$ value (from 3.26 to $3.08 \mathrm{eV}$ for $\mathrm{Ti}$ and Ce electrodes resp.) and simultaneously to a large increase in $R_{t}$ value (from 163 to $232 \Omega$ for Ti and Ce cells, resp.), best illustrates this effect. A situation described above may occur when an external layer has a narrower bandgap than $\mathrm{TiO}_{2}$, but the conducting band edge has still slightly more negative potential than the $\mathrm{TiO}_{2}$ conduction band edge.

The main goal of the covering of $\mathrm{TiO}_{2}$ electrodes with RE-containing layers was to enhance photoelectric parameters of DSSCs obtained. Figure 5 shows typical $J-V$ 
TABLE 1: The photoelectrochemical properties of the presented RE-modified photoelectrodes.

\begin{tabular}{|c|c|c|c|c|c|c|c|}
\hline $\mathrm{RE}$ & $E_{g}(\mathrm{eV})$ & $R_{t}(\Omega)$ & $N_{\text {dye }}\left(10^{-8} \mathrm{~mol} \mathrm{~cm}^{-2}\right)$ & $J_{\mathrm{sc}}\left(\mathrm{mA} \cdot \mathrm{cm}^{-2}\right)$ & $V_{\mathrm{oc}}(\mathrm{mV})$ & $\mathrm{FF}(\%)$ & $\eta(\%)$ \\
\hline $\mathrm{Ti}$ & 3.26 & 163 & 7.28 & 16.9 & 715 & 56.07 & 6.76 \\
\hline Sc & 3.23 & 205 & 6.66 & 19.2 & 737 & 44.58 & 6.30 \\
\hline Y & 3.21 & 144 & 7.60 & 17.0 & 674 & 44.52 & 5.11 \\
\hline $\mathrm{La}$ & 3.25 & 128 & 8.84 & 18.0 & 696 & 61.55 & 7.71 \\
\hline $\mathrm{Ce}$ & 3.08 & 232 & 6.52 & 19.3 & 730 & 63.06 & 8.88 \\
\hline $\operatorname{Pr}$ & 3.24 & 148 & 6.43 & 18.5 & 667 & 50.73 & 6.25 \\
\hline $\mathrm{Nd}$ & 3.28 & 136 & 7.35 & 18.9 & 683 & 55.33 & 7.15 \\
\hline $\mathrm{Sm}$ & 3.29 & 210 & 5.42 & 17.4 & 697 & 48.91 & 5.95 \\
\hline $\mathrm{Eu}$ & 3.33 & 131 & 5.85 & 18.2 & 663 & 46.14 & 5.55 \\
\hline Gd & 3.30 & 96 & 7.10 & 16.2 & 701 & 49.11 & 5.57 \\
\hline $\mathrm{Tb}$ & 3.28 & 175 & 7.87 & 17.9 & 718 & 56.66 & 7.29 \\
\hline Dy & 3.32 & 137 & 9.23 & 18.2 & 722 & 47.79 & 6.28 \\
\hline Ho & 3.33 & 245 & 7.74 & 17.8 & 716 & 58.95 & 7.49 \\
\hline Er & 3.24 & 137 & 6.33 & 18.6 & 712 & 53.17 & 7.03 \\
\hline $\mathrm{Tm}$ & 3.30 & 206 & 6.71 & 18.6 & 743 & 46.96 & 6.48 \\
\hline $\mathrm{Yb}$ & 3.23 & 100 & 7.41 & 19.8 & 702 & 63.21 & 8.80 \\
\hline $\mathrm{Lu}$ & 3.20 & 182 & 8.51 & 18.0 & 725 & 59.98 & 7.84 \\
\hline
\end{tabular}

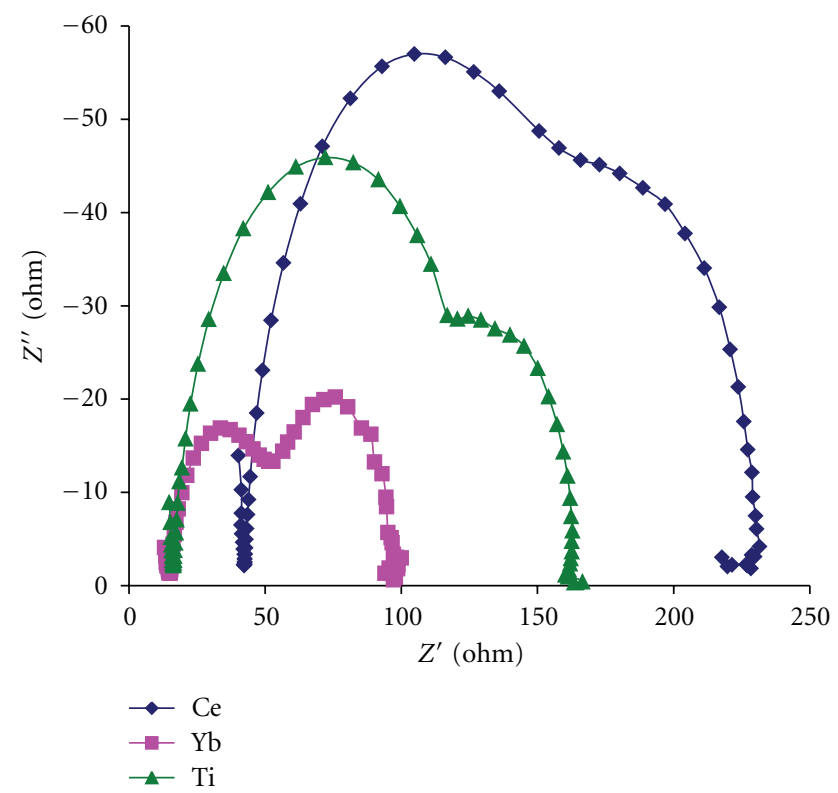

FIGURE 4: Electrochemical impedance analysis Nyquist Plots of two selected RE cells and Ti cell.

curves characterizing selected RE cells under illumination at AM $1.5 \mathrm{G}$ with the light intensity of $100 \mathrm{~mW} \cdot \mathrm{cm}^{-2}$. The values of the photovoltaic parameters, that is, short circuit photocurrent density $\left(J_{\mathrm{sc}}\right)$, open circuit photovoltage $\left(V_{\mathrm{oc}}\right)$, fill factor $(\mathrm{FF})$, and energy conversion efficiency $(\eta)$, determined for the cells investigated, are summarized in Table 1.

The $V_{\mathrm{oc}}$ parameters, which correspond to the Fermi level in the semiconductor and the Nernst potential of the redox couple in the electrolyte [3], for the cells studied vary between 663 and $743 \mathrm{mV}$ obtained for the Eu and Tm cells,

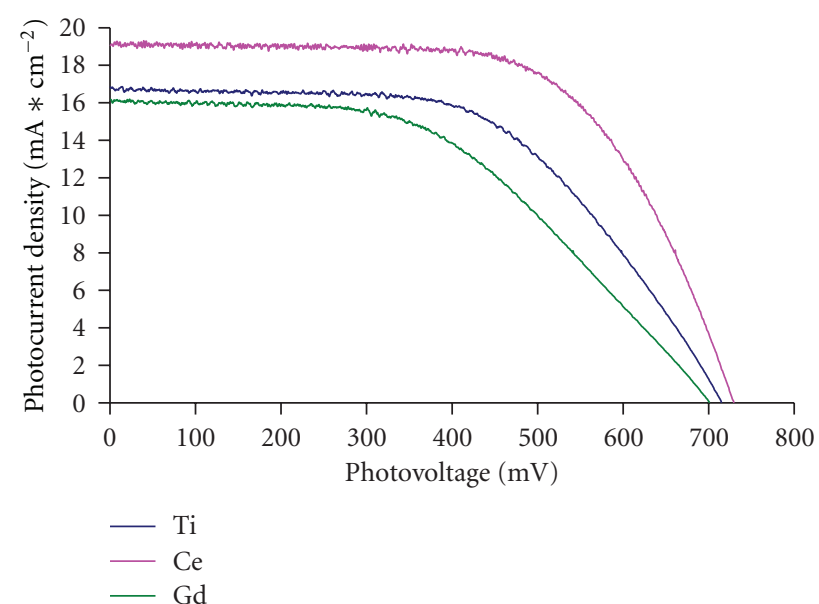

FIGURE 5: Photocurrent-photovoltage characteristics of selected solar cells investigated.

respectively. According to the $V_{\text {oc }}$ value obtained for Ti cell, the results for $\mathrm{RE}$ cells may be divided in three groups. The first group comprises Y, La, Pr, Nd, Sm, and Eu cells, whose $V_{\text {oc }}$ values are much lower than that of Ti cell, for the second group, including Gd, Tb, Ho, Er, and $\mathrm{Yb}$, the $V_{\mathrm{oc}}$ values are only slightly different from that for $\mathrm{Ti}$ cell and finally for the third group, including Sc, Ce, Dy, Tm and $\mathrm{Lu}$, the $V_{\mathrm{oc}}$ values are considerably higher than that of $\mathrm{Ti}$ cell. The increase in the photovoltage values of the cells from the third group, moreover, the $R_{t}$ values higher than that determined for $\mathrm{Ti}$ cell, suggests a formation of the energy barrier on the $\mathrm{TiO}_{2}$ surface as a result of its modification with RE belong to this group [42, 43]. Modification of the $\mathrm{TiO}_{2}$ electrode with a layer containing RE from the first and second groups has insignificant influence on the Fermi level 
of the electrode and, in consequence, leads to a decrease or only minor changes in the $V_{\text {oc }}$ values of the cells.

The photocurrent density of almost all RE cells presented, except Gd cell, has increased when compared with the value $16.9 \mathrm{~mA} \cdot \mathrm{cm}^{-2}$ obtained for Ti cell (see Table 1). The most important reasons for $J_{\mathrm{sc}}$ improvement are the increase in dye loading and enhancement in electron transport efficiency which depends on electron transport through the $\mathrm{TiO}_{2}$ film, prompt regeneration of the dye via electrolyte species, and prevention of the injected electron recombination process $[3,27,42,44]$. Analysis of the dye loading $\left(N_{\text {dye }}\right)$ values, collected in Table 1 , shows that only $\mathrm{Y}, \mathrm{La}, \mathrm{Nd}, \mathrm{Tb}, \mathrm{Dy}, \mathrm{Ho}, \mathrm{Yb}$ and $\mathrm{Lu}$ electrodes have higher $N_{\text {dye }}$ than Ti electrode, moreover, a significant increase in $N_{\text {dye }}$ value is not always connected with spectacular changes in $J_{\mathrm{sc}}$ value for example, La and Dy electrodes have much higher dye loading than Ti electrode $\left(8.84 \cdot 10^{-8}, 9.23 \cdot 10^{-8}\right.$ and $7.28 \cdot 10^{-8} \mathrm{M}$, resp.), but the increase in their $J_{\mathrm{sc}}$ values is not so spectacular $\left(18.0,18.2\right.$ and $16.9 \mathrm{mAcm}^{-2}$, resp.). For Sc, Ce, Pr, Sm, Eu, Er and Tm cells the $N_{\text {dye }}$ values are lower, however, the $J_{\mathrm{sc}}$ values are higher than that of Ti cell. Such an effect, that is, a lower dye loading leading to improvement in $J_{\mathrm{sc}}$, has been earlier observed for example, by Grätzel et al. [45]. In such cases, it can be assumed that the electron transportation process has such significant influence on the cell performance, that the decrease in the $N_{\text {dye }}$ value has a minor importance in the photocurrent generation process.

The fill factor values, which inform about the energy loss related to inherent resistance in the photovoltaic devices [46, 47], of the RE cells are from 44.52 to $63.21 \%$ for $\mathrm{Y}$ and $\mathrm{Yb}$ cells, respectively, (see Table 1). This range of the FF values is reasonable when, compared with, literature data [28].

Overall light-to-electrical energy conversion efficiency $(\eta)$ is a most important parameter characterizing DSSCs. The $\eta$ values obtained for RE cells are collected in Table 1. The efficiencies of $\mathrm{La}, \mathrm{Ce}, \mathrm{Nd}, \mathrm{Tb}, \mathrm{Ho}, \mathrm{Er}, \mathrm{Yb}$, and $\mathrm{Lu}$ cells are better than that of $\mathrm{Ti}$ cell. The highest efficiency is observed for Ce cell and is equal to $8.88 \%$, which is by about $31.4 \%$ higher than that of Ti cell $(\eta=6,76 \%)$. This spectacular improvement is a consequence of the formation an energy barrier (proved by the impedance measurements described above), which prevents the photoinjected electron back-transfer; additionally, the participation of the Ce $4 f$ orbitals in the $\mathrm{TiO}_{2}$ electron structure formation increases the excited electron lifetime and slows down the recombination effect [40]. The electron recombination prevention is most probably the main effect responsible for very good photoconversion efficiency of $\mathrm{Yb}$ cell $(8.80 \%)$. As follows from the $R_{t}$ value, in this cell, the energy barrier is not formed, moreover, the dye loading on $\mathrm{Yb}$ electrode is lower than for on $\mathrm{Ti}$ electrode, but the efficiency is improved. Besides the decrease in the electron recombination process, the light scattering effect through a Yb-containing layer has probably a significant influence on the $\mathrm{Yb}$ cell performance [23]. The most surprising result is a very low efficiency of Gd cell (5.57\%), as Gd-doping was earlier found to have positive influence on the DSSC performance by Lu et al. [28] and our previous studies [29]. Lu et al. have assumed a slightly different approach to the porous electrode

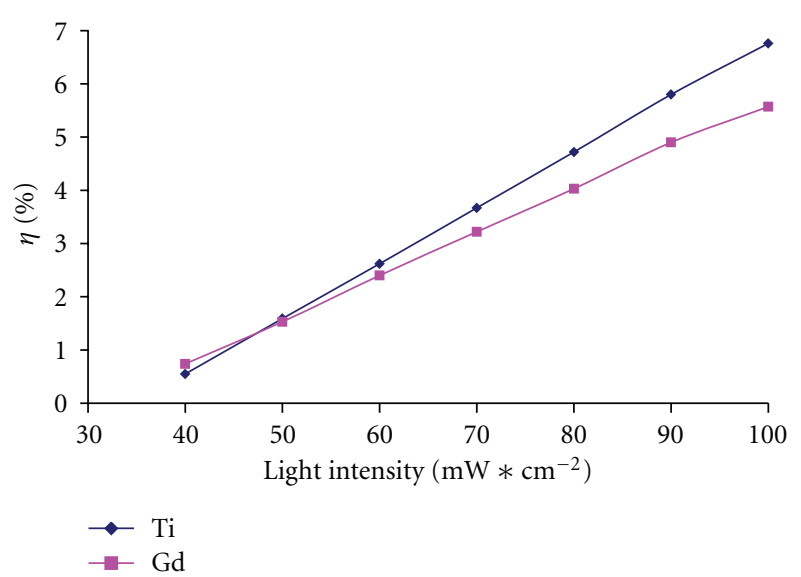

FIGURE 6: The relation between illumination intensity and overall photon-to-current efficiency of Ti and Gd cells.

modification leading to formation an external layer, with Gd oxide only [28]; our synthetic procedure was exactly the same as those published earlier [29]. The only differences between our previous study and this paper are the typical active areas of the cells investigated (approximately $1.5 \mathrm{~cm}^{2}$ and $0.125 \mathrm{~cm}^{2}$ ), the type of $J-V$ curves measuring system (self-made system and Keithley 2400), and the type and intensity of the light source (tungsten-halogen lamp with intensity of $40 \mathrm{~mW} \cdot \mathrm{cm}^{-2}$ and a class A Solar Simulator with intensity of $100 \mathrm{~mW} \cdot \mathrm{cm}^{-2}$ resp.). We decided to measure again the $J-V$ curves for $\mathrm{Gd}$ and $\mathrm{Ti}$ cells prepared in this study using our present light source and measuring system, under illumination with different light intensities in the range of $40-100 \mathrm{~mW} \cdot \mathrm{cm}^{-2}$ obtained by changing the distance between the light source and investigated cell. The results obtained are shown in Figure 6. The curves of the relationship between light intensity and overall photoconversion efficiency obtained for Ti and Gd cells show that the efficiency of the Gd cell is increasing slower than that of the $\mathrm{Ti}$ cell with the illumination power increasing. This effect leads to equalization of the cells efficiencies when light intensity is around $50 \mathrm{~mW} \cdot \mathrm{cm}^{-2}$ and the superiority of the Ti cell efficiency when the light intensity is over this value. This observation may lead to the conclusion that the modification of DSSC with a Gd-containing layer gives a cell, which may be used in the applications under not rich illumination.

\section{Conclusion}

The modifications of $\mathrm{TiO}_{2}$ electrodes by deposition of REcontaining external layers strongly influence the properties of the DSSCs fabricated using these electrodes, but have no effect on the crystal structure of the mesoporous electrode. $\mathrm{RE}$ introduction to the modifying layer causes changes in electronic properties of the materials obtained. The REcontaining layer may act as an energy barrier preventing electron back-transfer or as a light-scattering layer, but it also influences the excited electron transportation process 
and dye adsorption ability. All effects mentioned above cause that the fabricated DSSCs show wide ranges of the photoelectrochemical parameters with no specific trends. The performance of two most efficient DSSCs, containing $\mathrm{Ce}$ and $\mathrm{Yb}$ modified electrodes, depends on two different phenomena such us energy barrier formation and lightscattering, respectively. These two cells show 31.4 and $30.2 \%$ improvement in the overall photon-to-current efficiency when compared with that of the unmodified cell. Unfortunately, modifications with half of the RE investigated, that is, Sc, Y, Pr, Sm, Eu, Gd, Dy, and Tm, lead to a decrease in the photoconversion of relevant DSSCs.

\section{Acknowledgments}

This work was supported from the funds of Polish National Science Centre, Grant no. NN204 023538. The authors would like to thank Ms. Joanna Bludzińska from Evonik Degussa Poland for the donation of a P25 sample.

\section{References}

[1] B. O’Regan and M. Grätzel, "A low-cost, high-efficiency solar cell based on dye-sensitized colloidal $\mathrm{TiO}_{2}$ films," Nature, vol. 353, no. 6346, pp. 737-740, 1991.

[2] B. Li, L. Wang, B. Kang, P. Wang, and Y. Qiu, "Review of recent progress in solid-state dye-sensitized solar cells," Solar Energy Materials and Solar Cells, vol. 90, no. 5, pp. 549-573, 2006.

[3] A. Hagfeldt, G. Boschloo, L. Sun, L. Kloo, and H. Pettersson, "Dye-sensitized solar cells," Chemical Reviews, vol. 110, no. 11, pp. 6595-6663, 2010.

[4] G. C. Vougioukalakis, A. I. Philippopoulos, T. Stergiopoulos, and P. Falaras, "Contributions to the development of ruthenium-based sensitizers for dye-sensitized solar cells," Coordination Chemistry Reviews, vol. 255, no. 21-22, pp. 26022621, 2011.

[5] M. Grätzel, "Recent advances in sensitized mesoscopic solar cells," Accounts of Chemical Research, vol. 42, no. 11, pp. 1788 $1798,2009$.

[6] A. Hagfeldt and M. Grätzel, "Molecular photovoltaics," Accounts of Chemical Research, vol. 33, no. 5, pp. 269-277, 2000.

[7] M. Grätzel, "Dye-sensitized solar cells," Journal of Photochemistry and Photobiology C, vol. 4, no. 2, pp. 145-153, 2003.

[8] M. Grätzel, "Photoelectrochemical cells," Nature, vol. 414, no. 6861, pp. 338-344, 2001.

[9] S. Günes and N. S. Sariciftci, "Hybrid solar cells," Inorganica Chimica Acta, vol. 361, no. 3, pp. 581-588, 2008.

[10] C. Kim, K. S. Kim, H. Y. Kim, and Y. S. Han, "Modification of a $\mathrm{TiO}_{2}$ photoanode by using $\mathrm{Cr}$-doped $\mathrm{TiO}_{2}$ with an influence on the photovoltaic efficiency of a dye-sensitized solar cell," Journal of Materials Chemistry, vol. 18, no. 47, pp. 5809-5814, 2008.

[11] B. C. O'Regan, S. Scully, A. C. Mayer, E. Palomares, and J. Durrant, "The effect of $\mathrm{Al}_{2} \mathrm{O}_{3}$ barrier layers in $\mathrm{TiO}_{2} /$ Dye/CuSCN photovoltage cells explored by recombination and DOS characterization using transient photovoltage measurements," Journal of Physical Chemistry B, vol. 109, no. 10, pp. 46164623, 2005.

[12] Y. M. Lee, C. H. Hsu, and H. W. Chen, "Structural, optical, and electrical properties of p-type $\mathrm{NiO}$ films and composite
$\mathrm{TiO}_{2} / \mathrm{NiO}$ electrodes for solid-state dye-sensitized solar cells," Applied Surface Science, vol. 255, no. 8, pp. 4658-4663, 2009.

[13] S. Yang, H. Kou, S. Song, H. Wang, and W. Fu, “The enhanced photoelectric conversion efficiency of N3 sensitized $\mathrm{MgTiO}_{3}$ modified nanoporous $\mathrm{TiO}_{2}$ electrodes," Colloids and Surfaces $A$, vol. 340, no. 1-3, pp. 182-186, 2009.

[14] G. Wang, Q. Peng, and Y. Li, "Lanthanide-doped nanocrystals: synthesis, optical-magnetic properties, and applications," Accounts of Chemical Research, vol. 44, no. 5, pp. 322-332, 2011.

[15] A. W. Xu, Y. Gao, and H. Q. Liu, "The preparation, characterization, and their photocatalytic activities of rare-earth-doped $\mathrm{TiO}_{2}$ nanoparticles," Journal of Catalysis, vol. 207, no. 2, pp. 151-157, 2002.

[16] Q. Yao, J. Liu, Q. Peng, X. Wang, and Y. Li, "Nd-doped $\mathrm{TiO}_{2}$ nanorods: preparation and application in dye-sensitized solar cells," Chemistry, vol. 1, no. 5, pp. 737-741, 2006.

[17] H. Hafez, M. Saif, and M. S. A. Abdel-Mottaleb, "Downconverting lanthanide doped $\mathrm{TiO}_{2}$ photoelectrodes for efficiency enhancement of dye-sensitized solar cells," Journal of Power Sources, vol. 196, no. 13, pp. 5792-5796, 2011.

[18] H. Hafez, J. Wu, Z. Lan et al., "Enhancing the photoelectrical performance of dye-sensitized solar cells using $\mathrm{TiO}_{2}: \mathrm{Eu}^{3+}$ nanorods," Nanotechnology, vol. 21, no. 41, Article ID 415201, 2010.

[19] J. Wu, G. Xie, J. Lin, Z. Lan, M. Huang, and Y. Huang, "Enhancing photoelectrical performance of dye-sensitized solar cell by doping with europium-doped yttria rare-earth oxide," Journal of Power Sources, vol. 195, no. 19, pp. 69376940, 2010.

[20] J. H. Huang, P. Y. Hung, S. F. Hu, and R. S. Liu, "Improvement efficiency of a dye-sensitized solar cell using $\mathrm{Eu}^{3+}$ modified $\mathrm{TiO}_{2}$ nanoparticles as a secondary layer electrode," Journal of Materials Chemistry, vol. 20, no. 31, pp. 6505-6511, 2010.

[21] W. W. Xu, S. Y. Dai, L. H. Hu, L. Y. Liang, and K. J. Wang, "Influence of Yb-doped nanoporous $\mathrm{TiO}_{2}$ films on photovoltaic performance of dye-sensitized solar cells," Chinese Physics Letters, vol. 23, no. 8, pp. 2288-2291, 2006.

[22] Q. Li, J. Lin, J. Wu et al., "Enhancing photovoltaic performance of dye-sensitized solar cell by rare-earth doped oxide of $\mathrm{Lu}_{2} \mathrm{O}_{3}:\left(\mathrm{Tm}^{3+}, \mathrm{Yb}^{3+}\right)$," Electrochimica Acta, vol. 56, no. 14, pp. 4980-4984, 2011.

[23] G. Xie, Y. Wei, L. Fan, and J. Wu, "Application of doped rareearth oxide $\mathrm{TiO}_{2}:\left(\mathrm{Tm}^{3+}, \mathrm{Yb}^{3+}\right)$ in dye-sensitized solar cells," Journal of Physics: Conference Series, vol. 339, no. 1, Article ID 012010, 2012.

[24] J. Wang, J. Lin, J. Wu et al., "Application of $\mathrm{Yb}^{3+}, \mathrm{Er}^{3+}$-doped yttrium oxyfluoride nanocrystals in dye-sensitized solar cells," Electrochimica Acta, vol. 70, pp. 131-135, 2012.

[25] G. B. Shan and G. P. Demopoulos, "Near-infrared sunlight harvesting in dye-sensitized solar cells via the insertion of an upconverter- $\mathrm{TiO}_{2}$ nanocomposite layer," Advanced Materials, vol. 22, no. 39, pp. 4373-4377, 2010.

[26] C. H. Han, H. S. Lee, K. W. Lee, S. D. Han, and I. Singh, "Synthesis of amorphous $\mathrm{Er}^{3+}-\mathrm{Yb}^{3+} \mathrm{Co}$-doped $\mathrm{TiO}_{2}$ and its application as a scattering layer for dye-sensitized solar cells," Bulletin of the Korean Chemical Society, vol. 30, no. 1, pp. 219223, 2009.

[27] H. Yu, B. Xue, P. Liu et al., "High-performance nanoporous $\mathrm{TiO}_{2} / \mathrm{La} 2 \mathrm{O} 3$ hybrid photoanode for dye-sensitized solar cells," ACS Applied Materials \& Interfaces, vol. 4, no. 3, pp. 12891294, 2012.

[28] L. Lu, R. Li, T. Peng, K. Fan, and K. Dai, "Effects of rare earth ion modifications on the photoelectrochemical properties of 
ZnO-based dye-sensitized solar cells," Renewable Energy, vol. 36, no. 12, pp. 3386-3393, 2011.

[29] M. Zalas, M. Walkowiak, and G. Schroeder, "Increase in efficiency of dye-sensitized solar cells by porous $\mathrm{TiO}_{2}$ layer modification with gadolinium-containing thin layer," Journal of Rare Earths, vol. 29, no. 8, pp. 783-786, 2011.

[30] U. Opara Krašovec, M. Berginc, M. Hočevar, and M. Topič, "Unique $\mathrm{TiO}_{2}$ paste for high efficiency dye-sensitized solar cells," Solar Energy Materials and Solar Cells, vol. 93, no. 3, pp. 379-381, 2009.

[31] T. Ohno, K. Sarukawa, K. Tokieda, and M. Matsumura, "Morphology of a $\mathrm{TiO}_{2}$ photocatalyst (Degussa, P-25) consisting of anatase and rutile crystalline phases," Journal of Catalysis, vol. 203, no. 1, pp. 82-86, 2001.

[32] A. Hegazy and E. Prouzet, "Room temperature synthesis and thermal evolution of porous nanocrystalline $\mathrm{TiO}_{2}$ anatase," Chemistry of Materials, vol. 24, no. 2, pp. 245-254, 2011.

[33] F. Zhou, K. Kang, T. Maxisch, G. Ceder, and D. Morgan, "The electronic structure and band gap of $\mathrm{LiFePO}_{4}$ and $\mathrm{LiMnPO}_{4}$," Solid State Communications, vol. 132, no. 3-4, pp. 181-186, 2004.

[34] X. Chen and S. S. Mao, "Titanium dioxide nanomaterials: synthesis, properties, modifications and applications," Chemical Reviews, vol. 107, no. 7, pp. 2891-2959, 2007.

[35] C. Andrei, T. O’Reilly, and D. Zerulla, "A spatially resolved study on the Sn diffusion during the sintering process in the active layer of dye sensitised solar cells," Physical Chemistry Chemical Physics, vol. 12, no. 26, pp. 7241-7245, 2010.

[36] A. I. Martínez, L. Huerta, J. M. O-Rueda De León, D. Acosta, O. Malik, and M. Aguilar, "Physicochemical characteristics of fluorine doped tin oxide films," Journal of Physics D, vol. 39, no. 23, pp. 5091-5096, 2006.

[37] V. Štengl, S. Bakardjieva, and N. Murafa, "Preparation and photocatalytic activity of rare earth doped $\mathrm{TiO}_{2}$ nanoparticles," Materials Chemistry and Physics, vol. 114, no. 1, pp. 217226, 2009.

[38] M. Pal, U. Pal, J. M. G. Jimenez, and F. Perez-Rodriguez, "Effects of crystallization and dopant concentration on the emission behavior of $\mathrm{TiO}_{2}$ :Eu nanophosphors," Nanoscale Research Letters, vol. 7, article 1, 2012.

[39] S. W. Chen, J. M. Lee, K. T. Lu et al., "Band-gap narrowing of $\mathrm{TiO}_{2}$ doped with Ce probed with x-ray absorption spectroscopy," Applied Physics Letters, vol. 97, no. 1, Article ID 012104,2010

[40] H. Yang, K. Zhang, R. Shi, and A. Tang, "Sol-gel synthesis and photocatalytic activity of $\mathrm{CeO}_{2} / \mathrm{TiO}_{2}$ nanocomposites," Journal of the American Ceramic Society, vol. 90, no. 5, pp. 1370-1374, 2007.

[41] F. Fabregat-Santiago, J. Bisquert, G. Garcia-Belmonte, G. Boschloo, and A. Hagfeldt, "Influence of electrolyte in transport and recombination in dye-sensitized solar cells studied by impedance spectroscopy," Solar Energy Materials and Solar Cells, vol. 87, no. 1-4, pp. 117-131, 2005.

[42] S. K. Park, C. Kim, J. H. Kim, J. Y. Bae, and Y. S. Han, "Effects of $\mathrm{Mg}$ salt-modified $\mathrm{TiO}_{2}$ on the photovoltaic performance of dye-sensitized solar cells," Current Applied Physics, vol. 11, supplement, no. 1, pp. S131-S135, 2011.

[43] G. D. Sharma, P. Suresh, M. S. Roy, and J. A. Mikroyannidis, "Effect of surface modification of $\mathrm{TiO}_{2}$ on the photovoltaic performance of the quasi solid state dye sensitized solar cells using a benzothiadiazole-based dye," Journal of Power Sources, vol. 195, no. 9, pp. 3011-3016, 2010.

[44] F. Li and Y. Gu, "Improvement of performance of dyesensitized solar cells by doping $\mathrm{Er}_{2} \mathrm{O}_{3}$ into $\mathrm{TiO}_{2}$ electrodes,"
Materials Science in Semiconductor Processing, vol. 15, no. 1, pp. 11-14, 2012.

[45] T. T. Trang Pham, T. Bessho, N. Mathews et al., "Light scattering enhancement from sub-micrometer cavities in the photoanode for dye-sensitized solar cells," Journal of Materials Chemistry, vol. 22, no. 32, pp. 16201-16204, 2012.

[46] S. Biswas, M. F. Hossain, and T. Takahashi, "Fabrication of Grätzel solar cell with $\mathrm{TiO}_{2} / \mathrm{CdS}$ bilayered photoelectrode," Thin Solid Films, vol. 517, no. 3, pp. 1284-1288, 2008.

[47] B. Pradhan, S. K. Batabyal, and A. J. Pal, "Vertically aligned $\mathrm{ZnO}$ nanowire arrays in Rose Bengal-based dye-sensitized solar cells," Solar Energy Materials and Solar Cells, vol. 91, no. 9, pp. 769-773, 2007. 


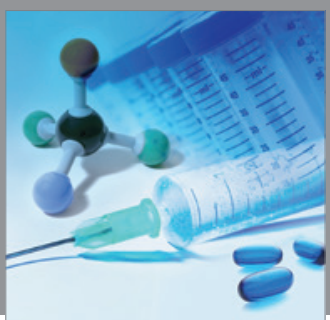

International Journal of

Medicinal Chemistry

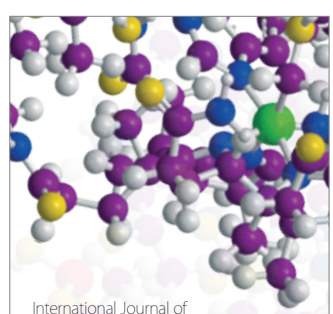

Carbohydrate Chemistry

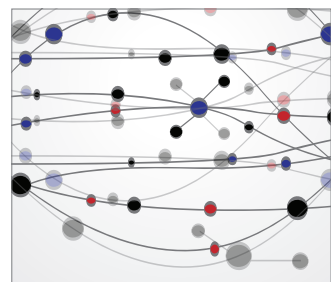

The Scientific World Journal
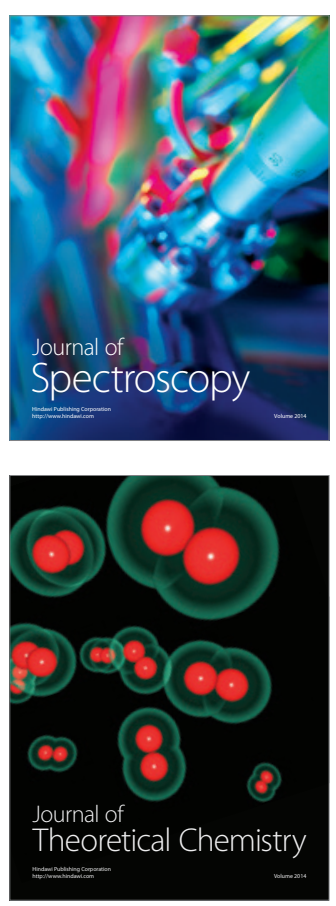
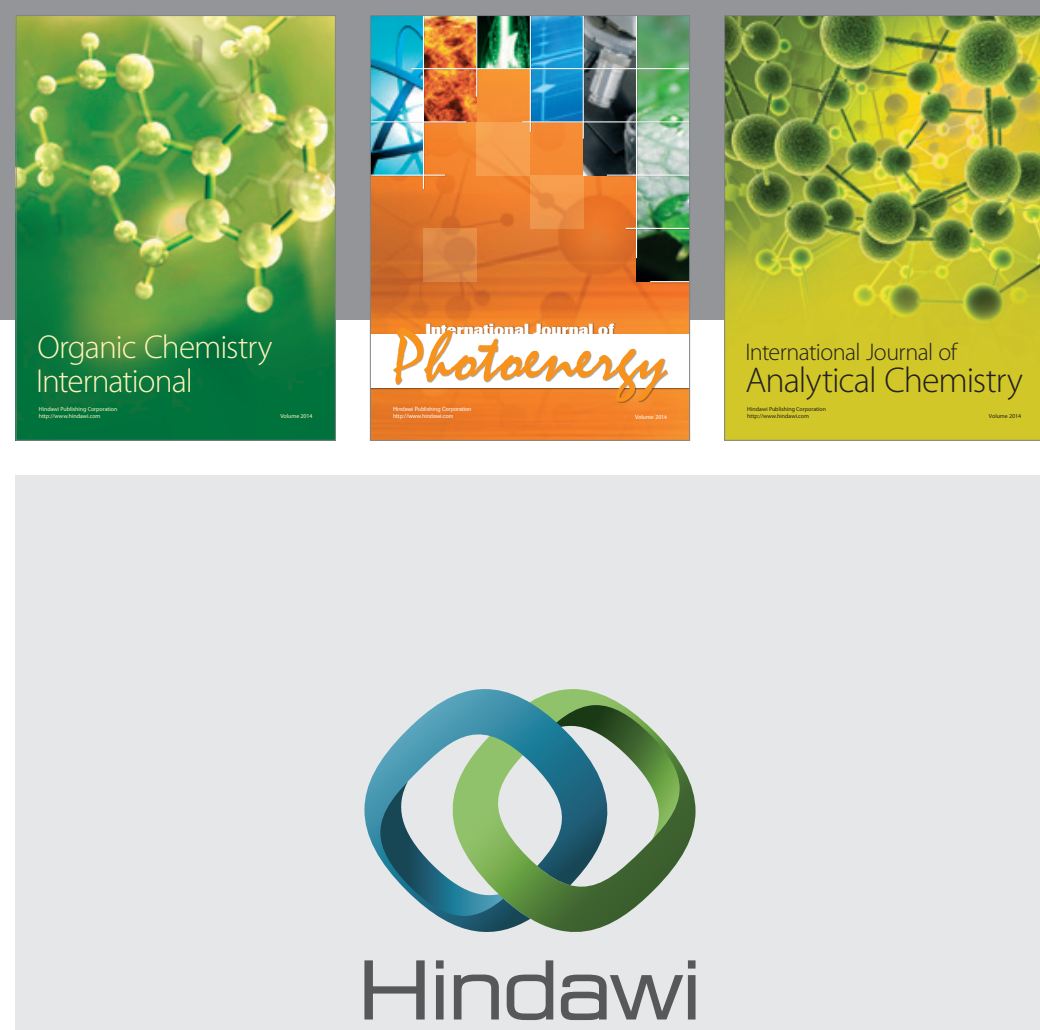

Submit your manuscripts at

http://www.hindawi.com
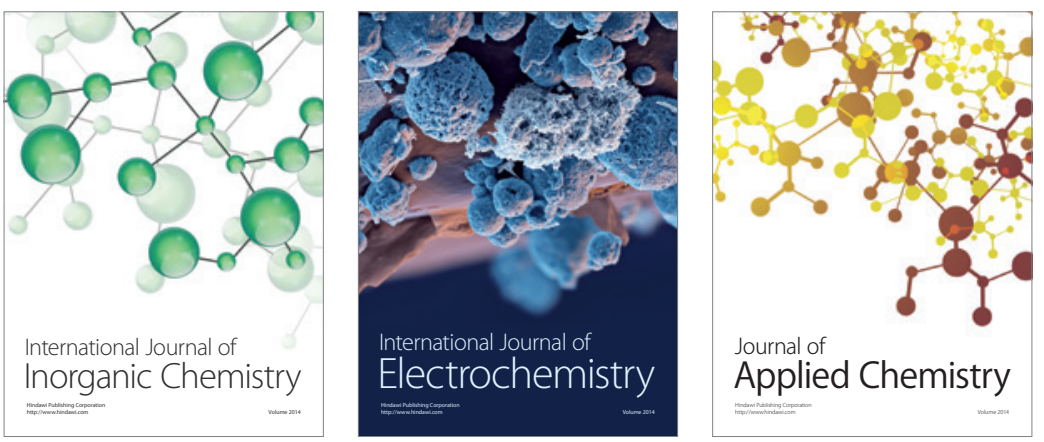

Journal of

Applied Chemistry
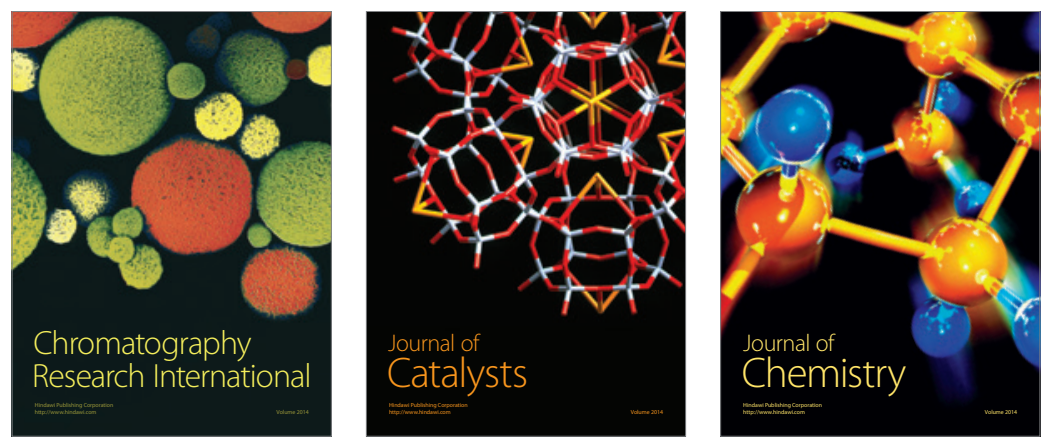
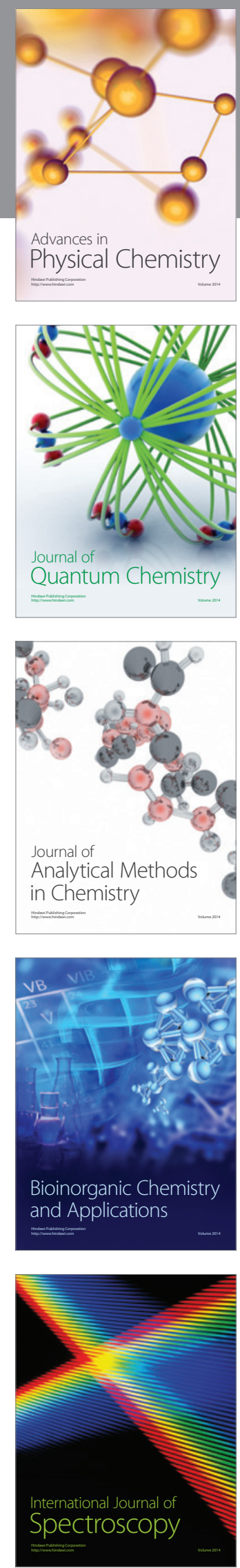